\title{
Variance and Passivity Constrained Fuzzy Control for Nonlinear Ship Steering Systems with State Multiplicative Noises
}

\author{
Wen-Jer Chang and Bo-Jyun Huang \\ Department of Marine Engineering, National Taiwan Ocean University, Keelung 202, Taiwan \\ Correspondence should be addressed to Wen-Jer Chang; wjchang@mail.ntou.edu.tw \\ Received 7 January 2013; Accepted 18 February 2013 \\ Academic Editor: Chang-Hua Lien
}

Copyright (C) 2013 W.-J. Chang and B.-J. Huang. This is an open access article distributed under the Creative Commons Attribution License, which permits unrestricted use, distribution, and reproduction in any medium, provided the original work is properly cited.

\begin{abstract}
The variance and passivity constrained fuzzy control problem for the nonlinear ship steering systems with state multiplicative noises is investigated. The continuous-time Takagi-Sugeno fuzzy model is used to represent the nonlinear ship steering systems with state multiplicative noises. In order to simultaneously achieve variance, passivity, and stability performances, some sufficient conditions are derived based on the Lyapunov theory. Employing the matrix transformation technique, these sufficient conditions can be expressed in terms of linear matrix inequalities. By solving the corresponding linear matrix inequality conditions, a parallel distributed compensation based fuzzy controller can be obtained to guarantee the stability of the closed-loop nonlinear ship steering systems subject to variance and passivity performance constraints. Finally, a numerical simulation example is provided to illustrate the usefulness and applicability of the proposed multiple performance constrained fuzzy control method.
\end{abstract}

\section{Introduction}

In the literature, the problem of controlling surface ships in maneuvering situations has been receiving more and more attention from the operational safety and environmental viewpoints [1-8]. For ship steering, the stochastic disturbances are waves, wind gusts, and observation errors, and the deterministic disturbances are current, mean wind, and curvature of the prespecified track. In order to deal with the complex disturbances, the adaptive control approach was developed to solve the ship steering control problem [1-4]. In [5], an output feedback control problem was studied by using the vectorial observer backstepping technique. Applying the sliding mode control, a multivariable performanceconstrained controller was developed in [6] for the dynamic ship positioning systems. In [1-6], the dynamic ship steering systems were approximated by the linearized models that may have sacrificed some nonlinear characteristics. In order to reserve the characteristics of original nonlinear systems, the authors of $[7,8]$ used the Takagi-Sugeno (T-S) fuzzy model to represent the nonlinear dynamic ship steering systems. Without loss of generality, the T-S fuzzy model $[7,8]$ can approximate a wide class of nonlinear systems by mixing several linear subsystems with IF-THEN rules.

In control engineering, it is always required to develop some methodologies for designing controllers to achieve multiple performance requirements. In addition to the stability performance constraint, the individual state variance constraint and passivity constraint are usually considered for the control problem of linear and nonlinear systems. The individual state variance performance requirements of engineering systems are usually expressed as upper bounds on the steady-state variances for the stochastic control systems. Current control design techniques, such as Linear Quadratic Gaussian (LQG) and $H_{\infty}$ design methods, do not seem to give a direct solution to this kind of design problem since they lack a convenient avenue for imposing design objectives stated in terms of upper bounds on the variance values. The covariance control theory developed in [9] provided a more direct methodology for achieving the individual variance constraints than the LQG control theory. The idea of covariance control theory has been widely applied in solving multiobjective control problems as well as filtering problems see $[6,10-13]$, for instance. In addition to the individual 


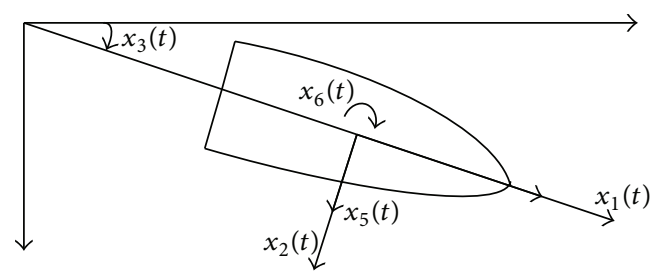

Figure 1: The coordinate of ship steering system.

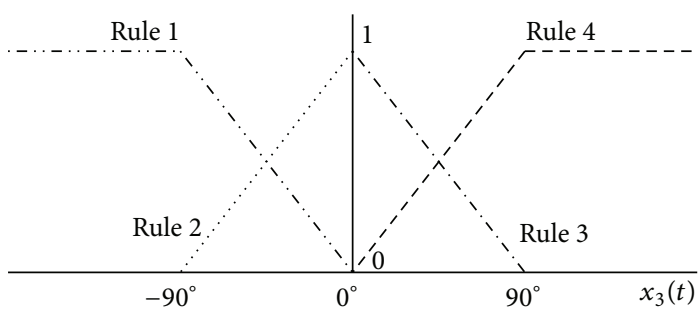

FIGURE 2: The membership function of state $x_{3}(t)$.

variance constraint, the passivity constraint is also considered in this paper. In the literature, the passivity concept [1421] is presented to issue stability analysis and synthesis of linear or nonlinear systems. It is well known that the passive theory uses the behaviors of energy dissipative between input and output of systems. The most important definitions of the passive theory are storage function $[16,20]$ and power supply $[16,21]$ for decision the property of passivity. As for a storage function in passive theory, it measures the amount of energy stored in the internal of the system; hence it is naturally described by using internal variables of system state variables. To the authors' knowledge, so far, the variance and passivity constrained stabilization problem of nonlinear stochastic ship steering systems with multiplicative noises has not been investigated. It is also an open problem to discuss the variance and passivity constrained fuzzy controller design for the stochastic T-S fuzzy models with multiplicative noises. For this reason, this paper tries to develop an applicable fuzzy control methodology for achieving the individual variance constraints and passivity constraints, simultaneously.

The control problem for the systems with multiplicative noise has recently received a great deal of attention. Such models are found in many physical systems, such as aerospace engineering systems [22], signal processing systems [23], and biological movement systems [24, 25]. Different from the traditional additive noise, multiplicative noise is more practical, since it allows the statistical description of the noise to be unknown a prior but depend on the control and state solution. So far, many researchers have been working on various kinds of investigation of filtering and control for the control systems with multiplicative noise. Thus, there have been several approaches for dealing with this problem, including the linear matrix inequality (LMI) approach [23], the Riccati difference equation approach [25], the game theoretic approach [26], and the fuzzy control approach [19, 27-29]. Since this model reflects more realistic properties in

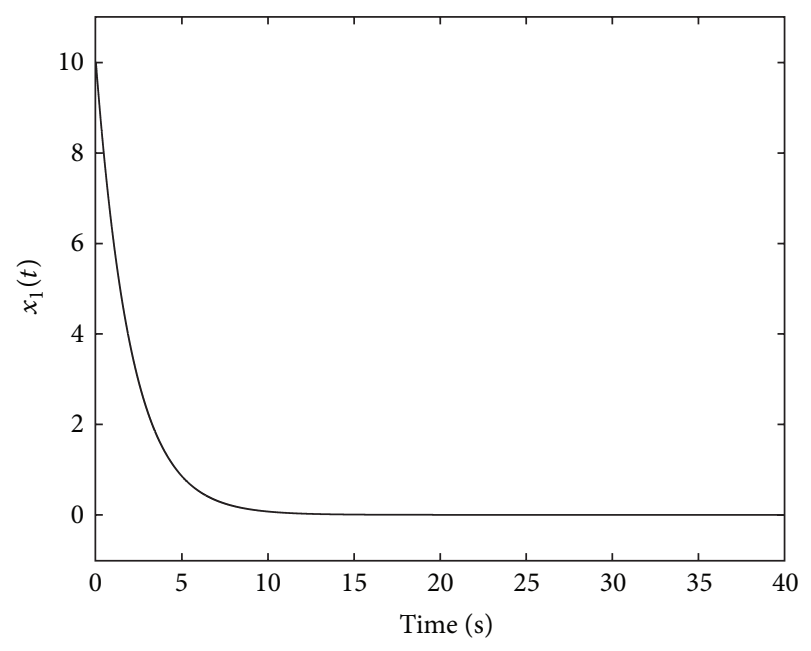

Figure 3: Responses of state $x_{1}(t)$.

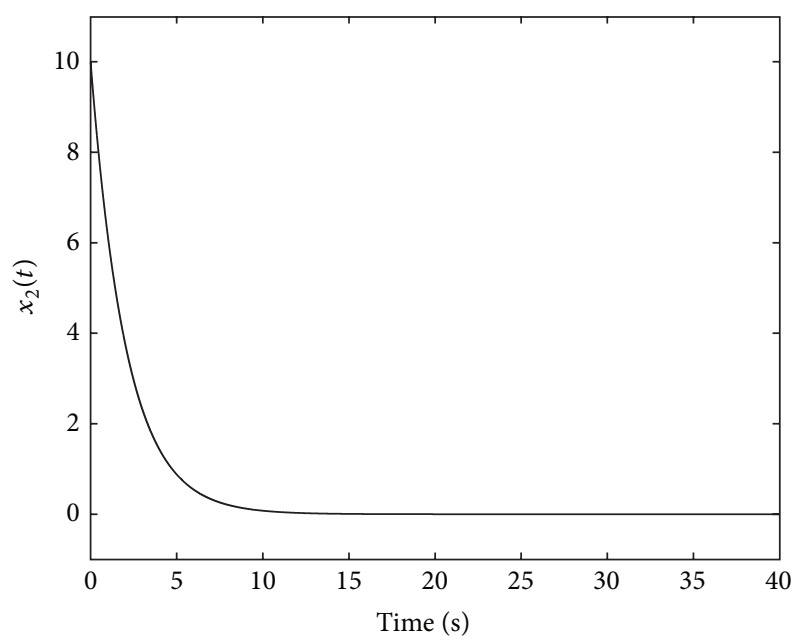

Figure 4: Responses of state $x_{2}(t)$.

engineering, a complete theory which includes control and estimation is worthy to be developed.

The contribution of this paper is to develop a methodology to design a fuzzy controller such that the stability constraint, individual variance constraint, and passivity constraint are simultaneously achieved for the nonlinear stochastic ship steering systems with multiplicative noise. The T-S fuzzy model is used to represent the nonlinear stochastic ship steering systems with multiplicative noise. According to the T-S fuzzy model with multiplicative noise, there are few approaches investigated to simultaneously achieve multiple performance requirements such as stability constraint, individual variance constraint, and passivity constraint. Therefore, the multiobjective fuzzy control methodology presented in this paper is worthy of the attention of control engineers. According to the T-S fuzzy model [30, 31], a parallel distributed compensation (PDC) [31] based fuzzy controller is designed via the Lyapunov theory in this paper. Subject to the individual variance constraint and passivity constraint, new sufficient conditions are derived by assigning 


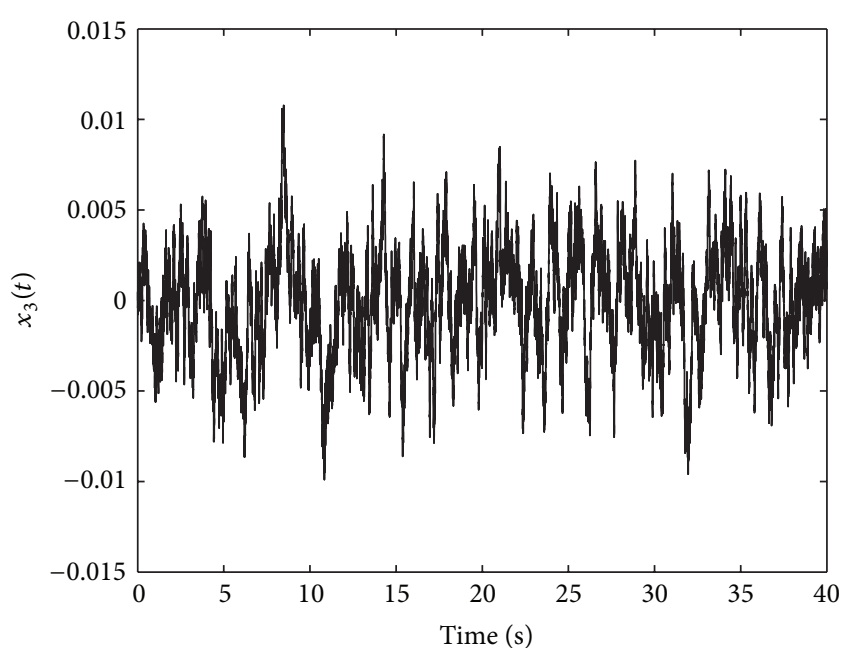

Figure 5: Responses of state $x_{3}(t)$.

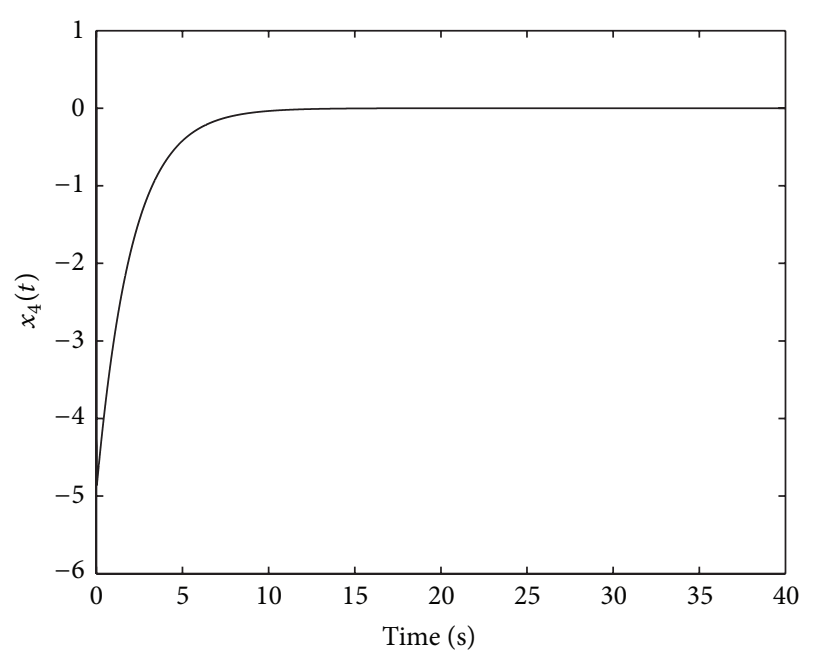

Figure 6: Responses of state $x_{4}(t)$.

a common upper bound matrix for the state covariance matrices of all fuzzy rules. By using the LMI technique [32] to solve the previous sufficient conditions, a PDC-based fuzzy controller can be obtained to guarantee the individual variance constraint and passivity constraint, simultaneously. Finally, a numerical example for controlling a nonlinear stochastic ship steering system with multiplicative noise is given to demonstrate the applicability and effectiveness of the proposed fuzzy controller design approach.

\section{System Description and Problem Statement}

Consider a nonlinear stochastic system, which is constructed by a continuous-time T-S fuzzy model with multiplicative noise as follows.
Rule i:

$$
\begin{aligned}
& \text { if } z_{1}(t) \text { is } M_{i 1} \cdots \text { and } z_{q}(t) \text { is } M_{i q} \\
& \text { then } \dot{x}(t)=\left[\begin{array}{r}
\left.\mathbf{A}_{i}+\sum_{e=1}^{m} \mathbf{N}_{e i} v_{e i}(t)\right] x(t) \\
+\mathbf{B}_{i} u(t)+\mathbf{D}_{i} w(t) \\
y(t)=\mathbf{C}_{i} x(t)+\mathbf{H}_{i} w(t)
\end{array}\right.
\end{aligned}
$$

where $z_{1}(t), \ldots, z_{q}(t)$ are the premise variables that may be functions of the state variables, $M_{i q}$ is the fuzzy set, $q$ is the premise variable number, $r$ is the number of fuzzy rules, $x(t) \in \mathfrak{R}^{n_{x}}$ is the state vector, $u(t) \in \mathfrak{R}^{n_{u}}$ is the input vector, $y(t) \in \mathfrak{R}^{n_{y}}$ is the output vector, and the processes $w(t) \in \mathfrak{R}^{n_{w}}$ and $v_{e i}(t) \in \mathfrak{R}$ are mutually independent zero-mean Gaussian white noise with intensities $\mathbf{W}(\mathbf{W}>$ 0 ) and 1, respectively. Referring to [33], it is assumed that $E\{w(t)\}=0, E\left\{v_{e i}(t)\right\}=0, E\{x(t) w(t)\}=E\{x(t)\} E\{w(t)\}=$ $0, E\left\{x(t) v_{e i}(t)\right\}=E\{x(t)\} E\left\{v_{e i}(t)\right\}=0$ and $E\left\{w(t) v_{e i}(t)\right\}=$ $E\{w(t)\} E\left\{v_{e i}(t)\right\}=0$. The matrices $\mathbf{A}_{i} \in \mathfrak{R}^{n_{x} \times n_{x}}, \mathbf{B}_{i} \in \mathfrak{R}^{n_{x} \times n_{u}}$, $\mathbf{D}_{i} \in \mathfrak{R}^{n_{x} \times n_{w}}, \mathbf{C}_{i} \in \mathfrak{R}^{n_{y} \times n_{x}}, \mathbf{H}_{i} \in \mathfrak{R}^{n_{y} \times n_{w}}$, and $\mathbf{N}_{e i} \in \mathfrak{R}^{n_{x} \times n_{x}}$ are constant.

Without loss of generality, it is assumed that the premise variables of the previous T-S fuzzy model are measurable. Given the pair $(x(t), u(t))$, the overall fuzzy model can be described as follows:

$$
\begin{aligned}
\dot{x}(t)= & \sum_{i=1}^{r} h_{i}(z(t)) \\
& \times\left\{\left[\mathbf{A}_{i}+\sum_{e=1}^{m} \mathbf{N}_{e i} v_{e i}(t)\right] x(t)+\mathbf{B}_{i} u(t)+\mathbf{D}_{i} w(t)\right\} \\
y(t)= & \sum_{i=1}^{r} h_{i}(z(t))\left\{\mathbf{C}_{i} x(t)+\mathbf{H}_{i} w(t)\right\}
\end{aligned}
$$

where $h_{i}(z(t))=\omega_{i}(z(t)) / \sum_{i=1}^{r} \omega_{i}(z(t)), \omega_{i}(z(t))=\prod_{j=1}^{q} M_{i j}$ $\left(z_{j}(t)\right), h_{i}(z(t)) \geq 0$, and $\sum_{i=1}^{r} h_{i}(z(t))=1$.

Applying the concept of PDC, the fuzzy controller is designed to share the same IF part of the T-S fuzzy model (1a) and (1b). The proposed fuzzy controller can be represented as follows.

Rule i:

$$
\begin{aligned}
& \text { if } z_{1}(t) \text { is } M_{i 1} \text { and } \cdots \text { and } z_{q}(t) \text { is } M_{i q} \\
& \text { then } u(t)=-\mathbf{F}_{i} x(t)
\end{aligned}
$$

or

$$
u(t)=\sum_{i=1}^{r} h_{i}(z(t))\left\{-\mathbf{F}_{i} x(t)\right\} .
$$


Substituting (4) into (2a), the closed-loop T-S fuzzy model can be obtained as follows:

$$
\begin{aligned}
\dot{x}(t)= & \sum_{i=1}^{r} \sum_{j=1}^{r} h_{i}(z(t)) h_{j}(z(t)) \\
& \times\left[\left(\mathbf{A}_{i}-\mathbf{B}_{i} \mathbf{F}_{j}\right) x(t)+\mathbf{D}_{i} w(t)+\sum_{e=1}^{m} \mathbf{N}_{e i} v_{e i}(t) x(t)\right] .
\end{aligned}
$$

Considering each subsystem of the T-S fuzzy model (5), the steady-state covariance matrix of the state vector $x(t)$ has the following form:

$$
\mathbf{X}_{i}=\mathbf{X}_{i}^{\mathrm{T}}>0
$$

where $\mathbf{X}_{i}=\lim _{t \rightarrow \infty} E\left[x(t) x^{\mathrm{T}}(t)\right]$ and $\mathbf{X}_{i}$ is the unique solution of the following Lyapunov equation for each rule [34]:

$$
\begin{aligned}
\left(\mathbf{A}_{i}-\right. & \left.\mathbf{B}_{i} \mathbf{F}_{i}\right) \mathbf{X}_{i}+\mathbf{X}_{i}\left(\mathbf{A}_{i}-\mathbf{B}_{i} \mathbf{F}_{i}\right)^{\mathrm{T}} \\
& +\mathbf{D}_{i} \mathbf{W D}_{i}^{\mathrm{T}}+\sum_{e=1}^{m} \mathbf{N}_{e i} \mathbf{X}_{i} \mathbf{N}_{e i}^{\mathrm{T}}=0, \quad i=1,2, \ldots, r .
\end{aligned}
$$

The state variance constraint considered in this paper is defined as follows:

$$
\left[\mathbf{X}_{i}\right]_{k k} \leq \sigma_{k}^{2}
$$

where $[\cdot]_{k k}$ denotes the $k$ th diagonal element of matrix $[\cdot]$ and $\sigma_{k}, k=1,2, \ldots, n_{x}$ denote the root-mean-squared constraints for the variance of system states. In addition to the previous individual state variance constraints (8), the passivity constraint introduced in the following definition is also considered in this paper.

Definition 1 (see [18]). The system (5) with external disturbance $w(t)$ and output $y(t)$ is called strictly input passive if there exists a positive scalar $\gamma$ and symmetric positive definite matrix $\mathbf{S}=\mathbf{S}^{\mathrm{T}}>0$ such that

$$
E\left\{2 \int_{0}^{t_{p}} y^{\mathrm{T}}(x) \mathbf{S} w(t) d t\right\}>E\left\{\int_{0}^{t_{p}} \gamma w^{\mathrm{T}}(t) w(t) d t\right\}
$$

for all $t_{p} \geq 0$ and $w(t) \neq 0$.

The purpose of this paper is to find feedback gains $\mathbf{F}_{i}$ that can be used to construct the PDC-based fuzzy controller (3) or (4) such that the individual state variance constraint (8) and passivity constraint (9) are all satisfied, simultaneously.

\section{Fuzzy Controller Design for T-S Fuzzy Models with Multiplicative Noises}

The sufficient conditions for guaranteeing the stability, individual variance constraint, and passivity constraint of closedloop T-S fuzzy model with multiplicative noise are derived in this section. By assigning a common upper bound matrix of the state covariance matrices for all fuzzy rules, the sufficient conditions are derived based on the Lyapunov theory and passivity theory. According to the closed-loop T-S fuzzy model (5), the sufficient conditions for achieving the stability, individual variance constraint, and passivity constraint are derived in the following theorem.

Theorem 2. If there exist positive definite matrices $\overline{\mathbf{X}}>0$ and $\mathbf{S}>0$ and feedback gains $\mathbf{F}_{i}$ and dissipative rate $\gamma$ satisfying the following sufficient conditions, then $\left[\mathbf{X}_{i}\right]_{k k} \leq \sigma_{k}^{2}$ and the closedloop system (5) is strictly input passive and asymptotically stable:

$$
\left[\begin{array}{cc}
\left(\mathbf{A}_{i}-\mathbf{B}_{i} \mathbf{F}_{i}\right) \overline{\mathbf{X}}+\overline{\mathbf{X}}\left(\mathbf{A}_{i}-\mathbf{B}_{i} \mathbf{F}_{i}\right)^{\mathrm{T}}+\mathbf{D}_{i} \mathbf{W} \mathbf{D}_{i}^{\mathrm{T}}+\sum_{e=1}^{m} \mathbf{N}_{e i} \overline{\mathbf{X}} \mathbf{N}_{e i}^{\mathrm{T}} & -\overline{\mathbf{X}} \mathbf{C}_{i}^{\mathrm{T}} \mathbf{S} \\
-\mathbf{S}^{\mathrm{T}} \mathbf{C}_{i} \overline{\mathbf{X}} & \gamma \mathbf{I}-\mathbf{H}_{i}^{\mathrm{T}} \mathbf{S}-\mathbf{S}^{\mathrm{T}} \mathbf{H}_{i}
\end{array}\right]<0
$$

$$
\begin{gathered}
\left(\frac{\mathbf{G}_{i j}+\mathbf{G}_{j i}}{2}\right) \overline{\mathbf{X}}+\overline{\mathbf{X}}\left(\frac{\mathbf{G}_{i j}+\mathbf{G}_{j i}}{2}\right)^{\mathrm{T}}<0, \quad \text { for } i<j \\
\overline{\mathbf{X}}-\operatorname{diag}\left(\sigma_{1}^{2}, \ldots, \sigma_{n_{x}}^{2}\right)<0
\end{gathered}
$$

where $\mathbf{G}_{i j}=\mathbf{A}_{i}-\mathbf{B}_{i} \mathbf{F}_{j}$ and $\operatorname{diag}\left(\sigma_{1}^{2}, \ldots, \sigma_{n_{x}}^{2}\right)$ denotes a diagonal matrix with the diagonal elements $\sigma_{1}^{2}, \sigma_{2}^{2}, \ldots$, and $\sigma_{n_{x}}^{2}$.

Proof. To analyze the stability of the closed-loop T-S fuzzy system (5), a Lyapunov function is chosen as $V(x(t))=$ $x^{\mathrm{T}}(t) \mathbf{P} x(t)$, where $\mathbf{P}=\mathbf{P}^{\mathrm{T}}>0$. The expected value of differential of the Lyapunov function $V(x(t))$ along the trajectories of (5) is given as follows:

$$
\begin{aligned}
& E\{\dot{V}(x(t))\} \\
& =E\left\{\dot{x}^{\mathrm{T}}(t) \mathbf{P} x(t)+x^{\mathrm{T}}(t) \mathbf{P} \dot{x}(t)\right\} \\
& =E\left\{\sum _ { i = 1 } ^ { r } h _ { i } ( z ( t ) ) \left\{\left[\mathbf{G}_{i i} x(t)+\mathbf{D}_{i} w(t)\right.\right.\right. \\
& \left.+\sum_{e=1}^{m} \mathbf{N}_{e i} v_{e i}(t) x(t)\right]^{\mathrm{T}}
\end{aligned}
$$




$$
\begin{aligned}
\times & \mathbf{P} x(t)+x^{\mathrm{T}}(t) \mathbf{P} \\
\times & {\left.\left[\mathbf{G}_{i i} x(t)+\mathbf{D}_{i} w(t)+\sum_{e=1}^{m} \mathbf{N}_{e i} v_{e i}(t) x(t)\right]\right\} } \\
+ & 2 \sum_{i<j}^{r} h_{i}(z(t)) h_{j}(z(t)) x^{\mathrm{T}}(t) \\
\times & \left.\left\{\left(\frac{\mathbf{G}_{i j}+\mathbf{G}_{j i}}{2}\right)^{\mathrm{T}} \mathbf{P}+\mathbf{P}\left(\frac{\mathbf{G}_{i j}+\mathbf{G}_{j i}}{2}\right)\right\} x(t)\right\} \\
=E\left\{\sum_{i=1}^{r} h_{i}(z(t))\right. & \\
\times & \left\{x ^ { \mathrm { T } } ( t ) \left[\mathbf{G}_{i i}^{\mathrm{T}} \mathbf{P}+\mathbf{P G}_{i i}\right.\right. \\
& \left.+w^{\mathrm{T}}(t) \mathbf{D}_{i}^{\mathrm{T}} \mathbf{P} x(t)+x^{\mathrm{T}}(t) \mathbf{D}_{i} w(t)\right\} \\
& +2 \sum_{i<j}^{r} h_{i}(z(t)) h_{j}(z(t)) x^{\mathrm{T}}(t) \\
& \times\left\{\left(\frac{\left.\left.\mathbf{G}_{i j}+\mathbf{G}_{j i}^{\mathrm{T}}(t) \mathbf{N}_{e i}^{\mathrm{T}} \mathbf{P}+\mathbf{P N}_{e i}^{\mathrm{T}} v_{e i}(t)\right)\right] x(t)}{2} \mathbf{P}+\mathbf{P}\left(\frac{\mathbf{G}_{i j}+\mathbf{G}_{j i}}{2}\right)\right\} x(t)\right\} .
\end{aligned}
$$

Due to $E\{x(t) w(t)\}=E\{x(t)\} E\{w(t)\}=0$ and $E\left\{x(t) v_{e i}(t)\right\}=$ $E\{x(t)\} E\left\{v_{e i}(t)\right\}=0$, one has

$$
\begin{aligned}
& E\{\dot{V}(x(t))\} \\
&=E\left\{\sum_{i=1}^{r} h_{i}(z(t))\left\{x^{\mathrm{T}}(t)\left[\mathbf{G}_{i i}^{\mathrm{T}} \mathbf{P}+\mathbf{P G}_{i i}\right] x(t)\right\}\right. \\
&+2 \sum_{i<j}^{r} h_{i}(z(t)) h_{j}(z(t)) x^{\mathrm{T}}(t) \\
&\left.\quad \times\left\{\left(\frac{\mathbf{G}_{i j}+\mathbf{G}_{j i}}{2}\right)^{\mathrm{T}} \mathbf{P}+\mathbf{P}\left(\frac{\mathbf{G}_{i j}+\mathbf{G}_{j i}}{2}\right)\right\} x(t)\right\} .
\end{aligned}
$$

It is obvious that if condition (10) is satisfied, then one has

$$
\begin{gathered}
\left(\mathbf{A}_{i}-\mathbf{B}_{i} \mathbf{F}_{i}\right) \overline{\mathbf{X}}+\overline{\mathbf{X}}\left(\mathbf{A}_{i}-\mathbf{B}_{i} \mathbf{F}_{i}\right)^{\mathrm{T}}+\mathbf{D}_{i} \mathbf{W} \mathbf{D}_{i}^{\mathrm{T}}+\sum_{e=1}^{m} \mathbf{N}_{e i} \overline{\mathbf{X}} \mathbf{N}_{e i}^{\mathrm{T}}<0 \\
\left(\mathbf{A}_{i}-\mathbf{B}_{i} \mathbf{F}_{i}\right) \overline{\mathbf{X}}+\overline{\mathbf{X}}\left(\mathbf{A}_{i}-\mathbf{B}_{i} \mathbf{F}_{i}\right)^{\mathrm{T}}
\end{gathered}
$$

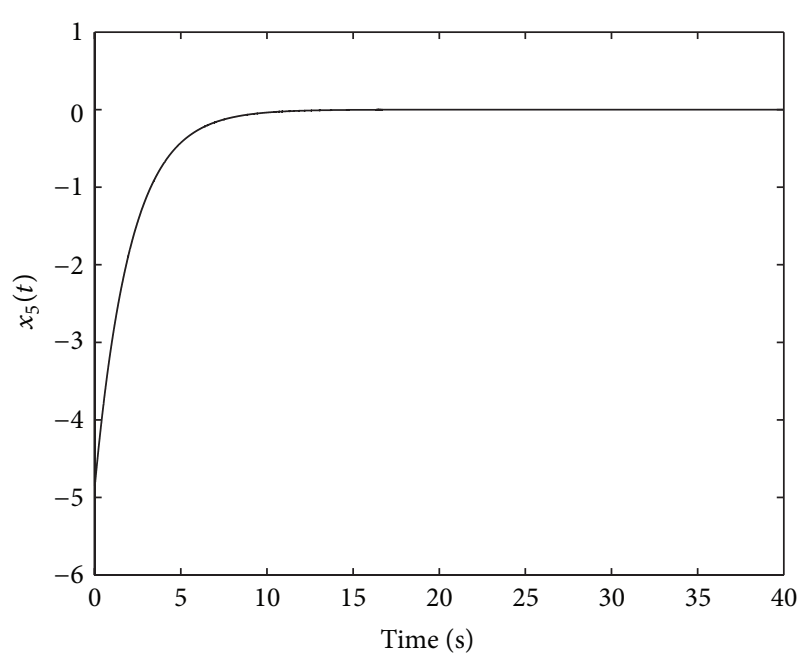

Figure 7: Responses of state $x_{5}(t)$.

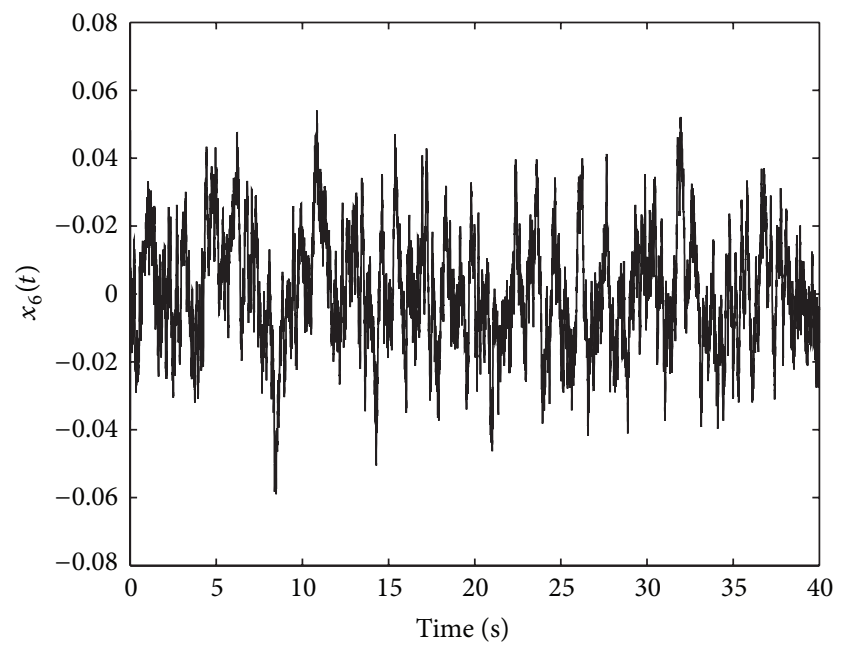

Figure 8: Responses of state $x_{6}(t)$.

Let $\mathbf{P}=\overline{\mathbf{X}}^{-1}$ and multiplying each item of the previous inequality from left-hand side and right-hand side by $\mathbf{P}$, then one can obtain the following inequality:

$$
\mathbf{G}_{i i}^{\mathrm{T}} \mathbf{P}+\mathbf{P G}_{i i}<0 .
$$

Besides, multiplying both sides of (11) by $\mathbf{P}$, one has

$$
\left(\frac{\mathbf{G}_{i j}+\mathbf{G}_{j i}}{2}\right)^{\mathrm{T}} \mathbf{P}+\mathbf{P}\left(\frac{\mathbf{G}_{i j}+\mathbf{G}_{j i}}{2}\right)<0 .
$$

It is obvious that if the conditions (17) and (18) are satisfied, then $E\{\dot{V}(x(t))\}<0$ can be obtained from (14). Thus, one can conclude that if conditions (10) and (11) are satisfied, then the closed-loop system (5) is asymptotically stable. 
Subtracting (7) from (15), one has

$$
\begin{gathered}
\left(\mathbf{A}_{i}-\mathbf{B}_{i} \mathbf{F}_{i}\right)\left(\overline{\mathbf{X}}-\mathbf{X}_{i}\right)+\left(\overline{\mathbf{X}}-\mathbf{X}_{i}\right)\left(\mathbf{A}_{i}-\mathbf{B}_{i} \mathbf{F}_{i}\right)^{\mathrm{T}} \\
+\sum_{e=1}^{m} \mathbf{N}_{e i}\left(\overline{\mathbf{X}}-\mathbf{X}_{i}\right) \mathbf{N}_{e i}^{\mathrm{T}}<0 .
\end{gathered}
$$

Due to the fact that conditions (10) and (11) are satisfied, one can obtain that the closed-loop system (5) is stable and the closed-loop system matrix $\left(\mathbf{A}_{i}-\mathbf{B}_{i} \mathbf{F}_{i}\right)$ is stable. In this case, it can be concluded that $\overline{\mathbf{X}}-\mathbf{X}_{i} \geq 0$ via inequality (19). From the condition (12) and $\overline{\mathbf{X}} \geq \mathbf{X}_{i}$, one has

$$
\left[\mathbf{X}_{i}\right]_{k k} \leq[\overline{\mathbf{X}}]_{k k} \leq \sigma_{k}^{2}
$$

For achieving the attenuating performance, the passivity theory provides a useful and effective tool to design the controller to achieve the energy constraints for the closedloop systems. Considering the passivity constraint defined in Definition 1 , one can define a performance function such as

$$
\begin{aligned}
& E\left\{\int_{0}^{t_{p}}\left(\gamma w^{\mathrm{T}}(t) w(t)-2 y^{\mathrm{T}}(x) \mathbf{S} w(t)\right) d t\right\} \\
& =E\left\{\int _ { 0 } ^ { t _ { p } } \left(\gamma w^{\mathrm{T}}(t) w(t)\right.\right. \\
& \left.\left.-2 y^{\mathrm{T}}(x) \mathbf{S} w(t)+\dot{V}(x(t))\right) d t-V(x(t))\right\} \\
& \leq E\left\{\int _ { 0 } ^ { t _ { p } } \left(\gamma w^{\mathrm{T}}(t) w(t)\right.\right. \\
& \triangleq E\{K(x, w, t)\},
\end{aligned}
$$

where

$$
\begin{aligned}
& K(x, w, t) \\
& \quad \triangleq \int_{0}^{t_{p}}\left(\gamma w^{\mathrm{T}}(t) w(t)-2 y^{\mathrm{T}}(x) \mathbf{S} w(t)+\dot{V}(x(t))\right) d t
\end{aligned}
$$

Using inequality (14) and Schur complement [32], one has

$$
\begin{aligned}
& E\{K(x, w, t)\} \\
&=E\left\{\sum_{i=1}^{r} h_{i}(z(t))\left[\begin{array}{c}
x(t) \\
w(t)
\end{array}\right]^{\mathrm{T}}\right. \\
& \\
& \times\left[\begin{array}{cc}
\mathbf{G}_{i i}^{\mathrm{T}} \mathbf{P}+\mathbf{P G}_{i i} & -\mathbf{C}_{i}^{\mathrm{T}} \mathbf{S} \\
-\mathbf{S}^{\mathrm{T}} \mathbf{C}_{i} & \gamma \mathbf{I}-\mathbf{H}_{i}^{\mathrm{T}} \mathbf{S}-\mathbf{S}^{\mathrm{T}} \mathbf{H}_{i}
\end{array}\right]\left[\begin{array}{c}
x(t) \\
w(t)
\end{array}\right] \\
&+2 \sum_{i<j}^{r} h_{i}(z(t)) h_{j}(z(t)) x^{\mathrm{T}}(t) \\
&\left.\times\left\{\left(\frac{\mathbf{G}_{i j}+\mathbf{G}_{j i}}{2}\right)^{\mathrm{T}} \mathbf{P}+\mathbf{P}\left(\frac{\mathbf{G}_{i j}+\mathbf{G}_{j i}}{2}\right)\right\} x(t)\right\} .
\end{aligned}
$$

Due to the fact $\mathbf{D}_{i} \mathbf{W} \mathbf{D}_{i}^{\mathrm{T}} \geq 0$ and $\sum_{e=1}^{m} \mathbf{N}_{e i} \overline{\mathbf{X}} \mathbf{N}_{e i}^{\mathrm{T}}>0$, it is obvious that condition (10) implies

$$
\left[\begin{array}{cc}
\left(\mathbf{A}_{i}-\mathbf{B}_{i} \mathbf{F}_{i}\right) \overline{\mathbf{X}}+\overline{\mathbf{X}}\left(\mathbf{A}_{i}-\mathbf{B}_{i} \mathbf{F}_{i}\right)^{\mathrm{T}} & -\overline{\mathbf{X}} \mathbf{C}_{i}^{\mathrm{T}} \mathbf{S} \\
-\mathbf{S}^{\mathrm{T}} \mathbf{C}_{i} \overline{\mathbf{X}} & \gamma \mathbf{I}-\mathbf{H}_{i}^{\mathrm{T}} \mathbf{S}-\mathbf{S}^{\mathrm{T}} \mathbf{H}_{i}
\end{array}\right]<0
$$

Multiplying inequality (24) on the left-hand and righthand sides by $\operatorname{diag}\{\mathbf{P}, \mathbf{I}\}$, then one can obtain the following inequality via $\mathbf{P}=\overline{\mathbf{X}}^{-1}$ :

$$
\left[\begin{array}{cc}
\mathbf{G}_{i i}^{\mathrm{T}} \mathbf{P}+\mathbf{P G}_{i i} & -\mathbf{C}_{i}^{\mathrm{T}} \mathbf{S} \\
-\mathbf{S}^{\mathrm{T}} \mathbf{C}_{i} & \gamma \mathbf{I}-\mathbf{H}_{i}^{\mathrm{T}} \mathbf{S}-\mathbf{S}^{\mathrm{T}} \mathbf{H}_{i}
\end{array}\right]<0
$$

If conditions (18) and (25) hold, then one can obtain $E\{K(x, w, t)\}<0$. From (22), the inequality $E\{K(x, w, t)\}<0$ implies

$$
E\left\{2 \int_{0}^{t_{p}} y^{\mathrm{T}}(x) \mathbf{S} w(t) d t\right\}>E\left\{\int_{0}^{t_{p}} \gamma w^{\mathrm{T}}(t) w(t) d t\right\}
$$

for all nonzero external disturbance. From Definition 1, it can be thus concluded that if conditions (10) and (11) are satisfied, then the closed-loop system (5) is strictly input passive.

Theorem 2 provides the sufficient conditions for solving the state feedback gains such that the closed-loop system (5) is asymptotically stable subject to individual state variance constraints and passivity constraint. The conditions derived in Theorem 2 cannot be solved by the LMI technique [32] because they are of the bilinear matrix inequality forms. In order to apply the LMI technique to solve the present problem, the conditions of Theorem 2 can be rewritten in the following corollary by using the matrix transform technique. 
Corollary 3. If there exist positive definite matrices $\overline{\mathbf{X}}>0$ and $\mathbf{S}>0$ and dissipative rate $\gamma$ and matrices $\mathbf{K}_{i}$ satisfying condition (12) and the following sufficient conditions, then $\left[\mathbf{X}_{i}\right]_{k k} \leq \sigma_{k}^{2}$ and the closed-loop system (5) is strictly input passive and asymptotically stable:

$$
\begin{gathered}
{\left[\begin{array}{cc}
\mathbf{A}_{i} \overline{\mathbf{X}}-\mathbf{B}_{i} \mathbf{K}_{i}+\overline{\mathbf{X}} \mathbf{A}_{i}-\mathbf{K}_{i}^{\mathrm{T}} \mathbf{B}_{i}^{\mathrm{T}}+\mathbf{D}_{i} \mathbf{W} \mathbf{D}_{i}^{\mathrm{T}}+\sum_{e=1}^{m} \mathbf{N}_{e i} \overline{\mathbf{X}} \mathbf{N}_{e i}^{\mathrm{T}} & -\overline{\mathbf{X}} \mathbf{C}_{i}^{\mathrm{T}} \mathbf{S} \\
-\mathbf{S}^{\mathrm{T}} \mathbf{C}_{i} \overline{\mathbf{X}} & \gamma \mathbf{I}-\mathbf{H}_{i}^{\mathrm{T}} \mathbf{S}-\mathbf{S}^{\mathrm{T}} \mathbf{H}_{i}
\end{array}\right]<0} \\
\left(\frac{\mathbf{A}_{i} \overline{\mathbf{X}}-\mathbf{B}_{i} \mathbf{K}_{j}+\mathbf{A}_{j} \overline{\mathbf{X}}-\mathbf{B}_{j} \mathbf{K}_{i}}{2}\right)+\left(\frac{\mathbf{A}_{i} \overline{\mathbf{X}}-\mathbf{B}_{i} \mathbf{K}_{j}+\mathbf{A}_{j} \overline{\mathbf{X}}-\mathbf{B}_{j} \mathbf{K}_{i}}{2}\right)^{\mathrm{T}}<0, \quad \text { for } i<j,
\end{gathered}
$$

where $\mathbf{K}_{i}=\mathbf{F}_{i} \overline{\mathbf{X}}$.

Proof. Consider conditions (10) and (11) of Theorem 2. By setting new variables $\mathbf{K}_{i}=\mathbf{F}_{i} \overline{\mathbf{X}}$, conditions (10) and (11) can be rewritten as (27) and (28), respectively. It is obvious that conditions (12) and (27)-(28) are of LMI forms for the desired parameters $\overline{\mathbf{X}}$ and $\mathbf{K}_{i}$.

Based on the conditions of Corollary 3, the fuzzy control gains can be solved via LMI technique [32] by using MATLAB LMI-Toolbox. In order to demonstrate the applicability and effectiveness of the proposed fuzzy controller design approach, a numerical example for the controller design problem of a nonlinear ship steering system is considered in the next section.

\section{Constrained Fuzzy Controller Design for Nonlinear Ship Steering Systems}

Consider a nonlinear ship steering system with state multiplicative noises. It is customary to write the dynamic equations using a coordinate frame fixed to the ship such as Figure 1. Its dynamic equation can be written as follows [7]:

$$
\begin{aligned}
& \dot{x}_{1}(t)= \cos \left(x_{3}(t)\right) x_{4}(t)-\sin \left(x_{3}(t)\right) x_{5}(t) \\
& \dot{x}_{2}(t)= \sin \left(x_{3}(t)\right) x_{4}(t)+\cos \left(x_{3}(t)\right) x_{5}(t) \\
& \dot{x}_{3}(t)=x_{6}(t)+0.3 w(t) \\
& \dot{x}_{4}(t)=-0.0358 x_{1}(t)-0.0797 x_{4}(t)+0.9215 u_{1}(t) \\
&+0.01 v_{1}(t) x_{4}(t)+0.005 v_{2}(t) x_{4}(t) \\
& \dot{x}_{5}(t)=-0.0208 x_{2}(t)-0.0818 x_{5}(t)-0.1224 x_{6}(t) \\
&+0.7802 u_{2}(t)+1.4811 u_{3}(t) \\
&+0.01 v_{1}(t) x_{5}(t)+0.007 v_{1}(t) x_{6}(t) \\
&+0.01 v_{2}(t) x_{5}(t)+0.005 v_{2}(t) x_{6}(t) \\
& \dot{x}_{6}(t)= 0.0394 x_{2}(t)-0.2254 x_{5}(t)-0.2468 x_{6}(t) \\
&+1.4811 u_{2}(t)+7.4562 u_{3}(t)
\end{aligned}
$$

Rule 2:

$$
\begin{aligned}
& \text { if } x_{3}(t) \text { is about } 0 \quad\left(-\frac{\pi}{2}<x_{3}<0\right) \\
& \text { then } \dot{x}(t)=\left[\mathbf{A}_{2}+\sum_{e=1}^{2} \mathbf{N}_{e 2} v_{e 2}(t)\right] \\
& \times x(t)+\mathbf{B}_{2} u(t)+\mathbf{D}_{2} w(t) \\
& y(t)=\mathbf{C}_{2} x(t)+\mathbf{H}_{2} w(t),
\end{aligned}
$$

where $x_{1}(t)$ and $x_{2}(t)$ are the earth-fixed positions $(x, y), x_{3}(t)$ is yaw angle of the ships, $x_{4}(t)$ is surge, $x_{5}(t)$ is sway, $x_{6}(t)$ is yaw modes, and $u(t)=\left[u_{1}(t) u_{2}(t) u_{3}(t)\right]^{\mathrm{T}}$ is the control and moment by the thruster system. Besides, the processes $v_{1}(t), v_{2}(t)$, and $w(t)$ are all mutually independent zero-mean Gaussian white noise with intensity 1.

In this paper, the previous nonlinear ship steering system is modeled by a T-S fuzzy model [31] by assuming that the yaw angle changes between $x_{3}(t) \in(-\pi / 2,+\pi / 2)$. The membership function of state $x_{3}(t)$ is given in Figure 2. The T-S fuzzy model for nonlinear ship steering systems contains the following rules.

Rule 1:

$$
\begin{aligned}
& \text { if } x_{3}(t) \text { is about }-\frac{\pi}{2} \quad\left(-\frac{\pi}{2}<x_{3}<0\right) \\
& \text { then } \dot{x}(t)=\left[\mathbf{A}_{1}+\sum_{e=1}^{2} \mathbf{N}_{e 1} v_{e 1}(t)\right] \\
& \times x(t)+\mathbf{B}_{1} u(t)+\mathbf{D}_{1} w(t) \\
& y(t)=\mathbf{C}_{1} x(t)+\mathbf{H}_{1} w(t),
\end{aligned}
$$


Rule 3:

$$
\begin{aligned}
& \text { if } x_{3}(t) \text { is about } 0 \quad\left(0<x_{3}<\frac{\pi}{2}\right) \\
& \text { then } \dot{x}(t)=\left[\mathbf{A}_{3}+\sum_{e=1}^{2} \mathbf{N}_{e 3} v_{e 3}(t)\right] \\
& \times x(t)+\mathbf{B}_{3} u(t)+\mathbf{D}_{3} w(t) \\
& y(t)=\mathbf{C}_{3} x(t)+\mathbf{H}_{3} w(t) .
\end{aligned}
$$

Rule 4:

$$
\begin{aligned}
& \text { if } x_{3}(t) \text { is about }+\frac{\pi}{2} \quad\left(0<x_{3}<\frac{\pi}{2}\right) \\
& \text { then } \dot{x}(t)=\left[\mathbf{A}_{4}+\sum_{e=1}^{2} \mathbf{N}_{e 4} v_{e 4}(t)\right] \\
& \times x(t)+\mathbf{B}_{4} u(t)+\mathbf{D}_{4} w(t) \\
& y(t)=\mathbf{C}_{4} x(t)+\mathbf{H}_{4} w(t),
\end{aligned}
$$

where

$$
\begin{aligned}
& \mathbf{A}_{1}=\left[\begin{array}{cccccc}
0 & 0 & 0 & \beta & 1 & 0 \\
0 & 0 & 0 & -1 & \beta & 0 \\
0 & 0 & 0 & 0 & 0 & 1 \\
-0.0358 & 0 & 0 & -0.0797 & 0 & 0 \\
0 & -0.0208 & 0 & 0 & -0.0818 & -0.1224 \\
0 & -0.0394 & 0 & 0 & -0.2254 & -0.2468
\end{array}\right] \text {, } \\
& \mathbf{A}_{2}=\left[\begin{array}{cccccc}
0 & 0 & 0 & 1 & \alpha & 0 \\
0 & 0 & 0 & -\alpha & 1 & 0 \\
0 & 0 & 0 & 0 & 0 & 1 \\
-0.0358 & 0 & 0 & -0.0797 & 0 & 0 \\
0 & -0.0208 & 0 & 0 & -0.0818 & -0.1224 \\
0 & -0.0394 & 0 & 0 & -0.2254 & -0.2468
\end{array}\right] \text {, } \\
& \mathbf{A}_{3}=\left[\begin{array}{cccccc}
0 & 0 & 0 & 1 & -\alpha & 0 \\
0 & 0 & 0 & \alpha & 1 & 0 \\
0 & 0 & 0 & 0 & 0 & 1 \\
-0.0358 & 0 & 0 & -0.0797 & 0 & 0 \\
0 & -0.0208 & 0 & 0 & -0.0818 & -0.1224 \\
0 & -0.0394 & 0 & 0 & -0.2254 & -0.2468
\end{array}\right] \text {, } \\
& \mathbf{A}_{4}=\left[\begin{array}{cccccc}
0 & 0 & 0 & \beta & -1 & 0 \\
0 & 0 & 0 & 1 & \beta & 0 \\
0 & 0 & 0 & 0 & 0 & 1 \\
-0.0358 & 0 & 0 & -0.0797 & 0 & 0 \\
0 & -0.0208 & 0 & 0 & -0.0818 & -0.1224 \\
0 & -0.0394 & 0 & 0 & -0.2254 & -0.2468
\end{array}\right] \text {, } \\
& \mathbf{B}_{1}=\mathbf{B}_{2}=\mathbf{B}_{3}=\mathbf{B}_{4}=\left[\begin{array}{cccccc}
0 & 0 & 0 & 0.9215 & 0 & 0 \\
0 & 0 & 0 & 0 & 0.7802 & 1.4811 \\
0 & 0 & 0 & 0 & 1.4811 & 7.4562
\end{array}\right]^{\mathrm{T}}
\end{aligned}
$$

$$
\begin{aligned}
& \mathbf{D}_{1}=\mathbf{D}_{2}=\mathbf{D}_{3}=\mathbf{D}_{4}=\left[\begin{array}{c}
0 \\
0 \\
0.3 \\
0 \\
0 \\
0
\end{array}\right] \\
& \mathbf{C}_{1}=\mathbf{C}_{2}=\mathbf{C}_{3}=\mathbf{C}_{4}=\left[\begin{array}{llllll}
0 & 0 & 1 & 0 & 0 & 0
\end{array}\right] \text {, } \\
& \mathbf{H}_{1}=\mathbf{H}_{2}=\mathbf{H}_{3}=\mathbf{H}_{4}=1 \text {. } \\
& \mathbf{N}_{11}=\mathbf{N}_{12}=\mathbf{N}_{13}=\mathbf{N}_{14}=\left[\begin{array}{cccccc}
0 & 0 & 0 & 0 & 0 & 0 \\
0 & 0 & 0 & 0 & 0 & 0 \\
0 & 0 & 0 & 0 & 0 & 0 \\
0 & 0 & 0 & 0.01 & 0 & 0 \\
0 & 0 & 0 & 0 & 0.01 & 0.007 \\
0 & 0 & 0 & 0 & 0.008 & 0.005
\end{array}\right] \text {, } \\
& \mathbf{N}_{21}=\mathbf{N}_{22}=\mathbf{N}_{23}=\mathbf{N}_{24}=\left[\begin{array}{cccccc}
0 & 0 & 0 & 0 & 0 & 0 \\
0 & 0 & 0 & 0 & 0 & 0 \\
0 & 0 & 0 & 0 & 0 & 0 \\
0 & 0 & 0 & 0.005 & 0 & 0 \\
0 & 0 & 0 & 0 & 0.01 & 0.005 \\
0 & 0 & 0 & 0 & 0.006 & 0.01
\end{array}\right] \text {, }
\end{aligned}
$$

and $\alpha=\sin \left(2^{\circ}\right)$ and $\beta=\cos \left(88^{\circ}\right)$.

In general, the PDC approach is a popular T-S fuzzy controller design method. In the PDC concept, one needs to first design a linear controller for each rule, after which the controller of the entire nonlinear system can be made by blending the linear controllers of all rules. The fuzzy controller produced using PDC is represented as follows.

Rule 1:

$$
\begin{aligned}
& \text { if } x_{3}(t) \text { is about }-\frac{\pi}{2} \quad\left(-\frac{\pi}{2}<x_{3}<0\right) \\
& \text { then } u(t)=-\mathbf{F}_{1} x(t)
\end{aligned}
$$

Rule 2:

$$
\begin{aligned}
& \text { if } x_{3}(t) \text { is about } 0 \quad\left(-\frac{\pi}{2}<x_{3}<0\right) \\
& \text { then } u(t)=-\mathbf{F}_{2} x(t)
\end{aligned}
$$

Rule 3:

$$
\begin{aligned}
& \text { if } x_{3}(t) \text { is about } 0 \quad\left(0<x_{3}<\frac{\pi}{2}\right) \\
& \text { then } u(t)=-\mathbf{F}_{3} x(t)
\end{aligned}
$$

Rule 4:

$$
\begin{aligned}
& \text { if } x_{3}(t) \text { is about } \frac{\pi}{2} \quad\left(0<x_{3}<\frac{\pi}{2}\right) \\
& \text { then } u(t)=-\mathbf{F}_{4} x(t),
\end{aligned}
$$


where $\mathbf{F}_{i}, i=1, \ldots, 4$, are the desired feedback gains for the fuzzy controller design.

For starting the fuzzy controller design, we select the supply rate $\gamma=1, \mathbf{S}=\mathbf{I}$ with compatible dimension and assign the individual state variance constraints as $\sigma_{1}^{2}=3$, $\sigma_{2}^{2}=3, \sigma_{3}^{2}=0.02, \sigma_{4}^{2}=2, \sigma_{5}^{2}=1$, and $\sigma_{6}^{2}=0.8$. Solving the sufficient conditions of Corollary 3 via LMI technique [32], the matrix $\overline{\mathbf{X}}$ and $\mathbf{F}_{i}$ can be obtained as follows:

$$
\begin{aligned}
& \overline{\mathbf{X}}=\left[\begin{array}{cccccc}
1.5365 & -1.6718 \times 10^{-11} & 1.5083 \times 10^{-10} & -0.7323 & 1.7508 \times 10^{-6} & -2.2125 \times 10^{-12} \\
-1.6718 \times 10^{-11} & 1.5056 & 1.4886 \times 10^{-8} & -1.7648 \times 10^{-6} & -0.7292 & 1.4989 \times 10^{-9} \\
1.5083 \times 10^{-10} & 1.4886 \times 10^{-8} & 0.0080 & 1.063 \times 10^{-12} & -1.4698 \times 10^{-9} & -0.0551 \\
-0.7323 & -1.7648 \times 10^{-6} & 1.063 \times 10^{-12} & 1.2898 & -1.016 \times 10^{-11} & -2.7184 \times 10^{-10} \\
1.7508 \times 10^{-6} & -0.7292 & -1.4698 \times 10^{-9} & -1.016 \times 10^{-11} & 0.7404 & 8.5979 \times 10^{-9} \\
-2.2125 \times 10^{-12} & 1.4989 \times 10^{-9} & -0.0551 & -2.7184 \times 10^{-10} & 8.5979 \times 10^{-9} & 0.5004
\end{array}\right], \\
& \mathbf{F}_{1}=\left[\begin{array}{cccccc}
111.3 & -2.3 & -0.7 & 228 & -3.3 & -0.1 \\
1 & 958 & -529.3 & 0.6 & 1970.8 & -93.2 \\
-0.2 & -200.2 & 1126.1 & -0.1 & -411.9 & 202.8
\end{array}\right], \quad \mathbf{F}_{2}=\left[\begin{array}{cccccc}
112.4 & 0.021 & -10.5 & 228.8 & 0.1 & -1.9 \\
-0.1 & 914.6 & -4446.3 & -0.2 & 1880 & -804 \\
0.0301 & -176.6 & 1904.2 & 0.1 & -362.9 & 344
\end{array}\right], \\
& \mathbf{F}_{3}=\left[\begin{array}{cccccccc}
112.4 & 0.9 & -25.7 & 228.8 & 1.9 & -4.7 \\
-0.5 & 940 & -2271.7 & -1.1 & 1932.2 & -409.4 \\
0.2 & -189.9 & 1472.2 & 0.3 & -390.5 & 265.6
\end{array}\right], \quad \mathbf{F}_{4}=\left[\begin{array}{cccccc}
111.3 & 2.6 & -6.2 & 228 & 3.8 & -1.1 \\
-1.1 & 916.8 & -4058.7 & -0.9 & 1886 & 733.7 \\
0.2 & -178.5 & 1827.2 & 0.2 & -367.2 & 330
\end{array}\right] .
\end{aligned}
$$

The simulation responses of states are shown in Figures $3,4,5,6,7,8$ with initial condition $x(0)=\left[\begin{array}{lllll}10 & 10 & 0 & 0 & 0\end{array}\right]^{\mathrm{T}}$. Besides, the external disturbances $v_{1}(t), v_{2}(t)$, and $w(t)$ are chosen as zero-mean white noises with variance one. From the simulation results, the effect of the external disturbance $w(t)$ on the proposed system can be criticized as follows:

$$
\frac{E\left\{2 \int_{0}^{t_{p}} y^{\mathrm{T}}(x) \mathbf{S} w(t) d t\right\}}{E\left\{\int_{0}^{t_{p}} \gamma w^{\mathrm{T}}(t) w(t) d t\right\}}=2.0004 .
$$

The ratio value of (33) is bigger than determined dissipation rate $\gamma=1$; one can find that condition (9) of Definition 1 is satisfied. Besides, the variances of states $x_{1}(t), x_{2}(t), x_{3}(t)$, $x_{4}(t), x_{5}(t)$, and $x_{6}(t)$ are $2.4692,2.4849,8.8252 \times 10^{-6}$, $0.5876,0.5825$, and $2.771 \times 10^{-4}$, respectively. It is obvious that the individual state variance constraints are all satisfied. Therefore, the nonlinear ship steering system (29a), (29b), (29c), (29d), (29e), and (29f) controlled by the proposed fuzzy controller (31a), (31b), (31c), and (31d) is asymptotically stable subject to individual state variance constraints and strictly input passivity constraint.

\section{Conclusions}

The performance-constrained fuzzy controller design problem for the nonlinear ship steering system has been studied in this paper. The nonlinear ship steering system was modeled by a stochastic T-S fuzzy model with state multiplicative noises. This paper also considered the individual state variance constraint and passivity constraint. Based on the PDC concept, the proposed fuzzy controller design approach was carried out by solving the LMI stability conditions. On the other hand, these LMI stability conditions can be solved by the convex optimal programming algorithm. In the numerical example, a nonlinear ship steering system has been introduced to illustrate the usefulness and effectiveness of the proposed fuzzy control methodology.

\section{Acknowledgments}

The authors would like to express their sincere gratitude to anonymous reviewers who gave them some constructive comments, criticisms, and suggestions. This work was supported by the National Science Council of the Republic of China under Contract NSC101-2221-E-019-036.

\section{References}

[1] P. T. K. Fung and M. J. Grimble, "Dynamic ship positioning using a self-tuning kalman filter," IEEE Transactions on Automatic Control, vol. AC-28, no. 3, pp. 339-350, 1983.

[2] J. V. Aneronger, "Adaptive steering of ships-a model reference approach," Automatica, vol. 20, no. 1, pp. 3-14, 1984.

[3] R. E. Reid, A. K. Tugcu, and B. C. Mears, "The use of wave filter design in kalman filter state estimation of the automatic steering problem of a tanker in a seaway," IEEE Transactions on Automatic Control, vol. AC-29, no. 7, pp. 577-584, 1984.

[4] J. M. Godhavn, T. I. Fossen, and S. P. Berge, "Non-linear and adaptive backstepping designs for tracking control of ships," International Journal of Adaptive Control and Signal Processing, vol. 12, no. 8, pp. 649-670, 1998.

[5] T. I. Fossen and A. Grovlen, "Nonlinear output feedback control of dynamically positioned ships using vectorial observer backstepping," IEEE Transactions on Control Systems Technology, vol. 6, no. 1, pp. 121-128, 1998.

[6] W. J. Chang and K. Y. Chang, "Multivariable performanceconstrained sliding mode control for ship Yaw-motion systems with perturbations," International Journal of Adaptive Control and Signal Processing, vol. 14, no. 4, pp. 393-409, 2000.

[7] H. Y. Chung, S. M. Wu, and W. J. Chang, "Regional fuzzy control for nonlinear ship steering systems," International Journal of 
Innovative Computing, Information and Control, vol. 4, no. 7, pp. 1635-1646, 2008.

[8] W. J. Chang, H. J. Liang, and C. C. Ku, "Fuzzy controller design subject to actuator saturation for dynamic ship positioning systems with multiplicative noises," Proceedings of the Institution of Mechanical Engineers. Part I: Journal of Systems and Control Engineering, vol. 224, no. 6, pp. 725-736, 2010.

[9] A. Hotz and R. E. Skelton, "Covariance control theory," International Journal of Control, vol. 46, no. 1, pp. 13-32, 1987.

[10] W. J. Chang and H. Y. Chung, "A study of $H_{\infty}$ norm and variance-constrained design using dynamic output feedback for linear discrete systems," International Journal of Control, vol. 57, no. 2, pp. 473-483, 1993.

[11] W. J. Chang and J. N. Lin, "Robust dynamic controller design with multi-constraints for linear perturbed discrete systems," Asia Journal of Control, vol. 5, no. 4, pp. 235-241, 1997.

[12] Y. Hung and F. Yang, "Robust $H_{\infty}$ filtering with error variance constraints for uncertain discrete time-varying systems with uncertainty," Automatica, vol. 39, no. 7, pp. 1185-1194, 2003.

[13] S. Baromand and H. Khaloozadeh, "On the closed-form model for state covariance assignment problem," IET Control Theory \& Applications, vol. 4, no. 9, pp. 1678-1686, 2010.

[14] C. I. Byrnes, A. Isidori, and J. C. Willems, "Passivity, feedback equivalence, and the global stabilization of minimum phase nonlinear systems," IEEE Transactions on Automatic Control, vol. 36, no. 11, pp. 1228-1240, 1991.

[15] L. Xie, M. Fu, and H. Li, "Passivity analysis and passification for uncertain signal processing systems," IEEE Transactions on Signal Processing, vol. 46, no. 9, pp. 2394-2403, 1998.

[16] R. Lozano, B. Brogliato, O. Egeland, and B. Maschke, Dissipative Systems Analysis and Control Theory and Application, Springer, London, USA, 2000.

[17] W.-J. Chang, C. C. Ku, and W. Chang, "Analysis and synthesis of discrete nonlinear passive systems via affine T-S fuzzy models," International Journal of Systems Science, vol. 39, no. 8, pp. 809821, 2008.

[18] W.-J. Chang, C.-C. Ku, and P.-H. Huang, "Robust fuzzy control for uncertain stochastic time-delay Takagi-Sugeno fuzzy models for achieving passivity," Fuzzy Sets and Systems, vol. 161, no. 15, pp. 2012-2032, 2010.

[19] W. J. Chang, S. S. Jheng, and C. C. Ku, "Fuzzy control with robust and passive properties for discrete-time Takagi-Sugeno fuzzy systems with multiplicative noises," Proceedings of the Institution of Mechanical Engineers. Part I: Journal of Systems and Control Engineering, vol. 226, no. 4, pp. 476-485, 2012.

[20] O. Kaneko and T. Fujii, "On discrete time nonnegative storage functions and state functions," in Proceedings of the 39th IEEE Confernce on Decision and Control, vol. 4, pp. 3169-3174, December 2000.

[21] J. Mohseni, E. Yaz, and K. Olejniczak, "State-dependent LMI control of discrete-time nonlinear systems," in Proceedings of the 37th IEEE Conference on Decision and Control (CDC '98), pp. 4626-4627, December 1998.

[22] S. M. Joshi, "On optimal control of linear systems in the presence of multiplicative noise," IEEE Transactions on Aerospace and Electronic Systems, vol. AES-12, no. 1, pp. 80-85, 1976.

[23] E. Gershon, U. Shaked, and I. Yaesh, " $H_{\infty}$ control and filtering of discrete-time stochastic systems with multiplicative noise," Automatica, vol. 37, no. 3, pp. 409-417, 2001.

[24] C. M. Harris and D. M. Wolpert, "Signal-dependent noise determines motor planning," Nature, vol. 394, no. 6695, pp. 780-784, 1998.
[25] E. Todorov, "Stochastic optimal control and estimation methods adapted to the noise characteristics of the sensorimotor system," Neural Computation, vol. 17, no. 5, pp. 1084-1108, 2005.

[26] Y. A. Phillis, "Estimation and control of systems with unknown covariance and multiplicative noise," IEEE Transactions on Automatic Control, vol. 34, no. 10, pp. 1075-1078, 1989.

[27] W. J. Chang, W. Y. Wu, and C. C. $\mathrm{Ku}$, " $H_{\infty}$ constrained fuzzy control via state observer feedback for discrete-time Takagi-Sugeno fuzzy systems with multiplicative noises," ISA Transactions, vol. 50, no. 1, pp. 37-43, 2011.

[28] W. J. Chang, L. Z. Liu, and C. C. Ku, "Passive fuzzy controller design via observer feedback for stochastic Takagi-Sugeno fuzzy models with multiplicative noises," International Journal of Control, Automation, and Systems, vol. 9, no. 3, pp. 550-557, 2011.

[29] H. T. Yau, C. C. Wang, C. T. Hsieh, and C. C. Cho, "Nonlinear analysis and control of the uncertain micro-electro-mechanical system by using a fuzzy sliding mode control design," Computers and Mathematics with Applications, vol. 61, no. 8, pp. 1912-1916, 2011.

[30] L. Huang, K. Wang, P. Shi, and H. R. Karimi, "A novel identification method for generalized T-S fuzzy systems," Mathematical Problems in Engineering, vol. 2012, Article ID 893807, 12 pages, 2012.

[31] K. Tanaka and H.O. Wang, Fuzzy Control Systems Design and Analysis: A Linear Matrix Inequality Approach, John Wiley \& Sons, 2001.

[32] S. Boyd, L. El Ghaoui, E. Feron, and V. Balakrishnan, Linear Matrix Inequalities in System and Control Theory, vol. 15, SIAM, Philadelphia, Pa, USA, 1994.

[33] G. Eli, S. Uri, and Y. Isaac, $H_{\infty}$ Control and Estimation of StateMultiplicative Linear Systems, Springer, London, UK, 2005.

[34] H. Y. Chung and W. J. Chang, "Constrained variance design for bilinear stochastic continuous systems," IEE Proceedings D, vol. 138, no. 2, pp. 145-150, 1991. 


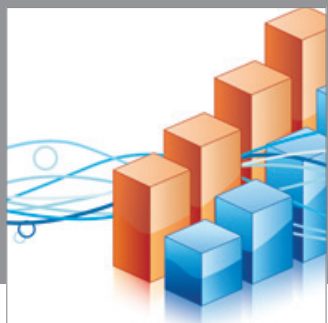

Advances in

Operations Research

mansans

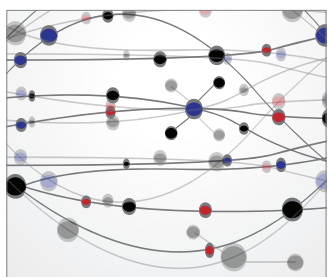

The Scientific World Journal
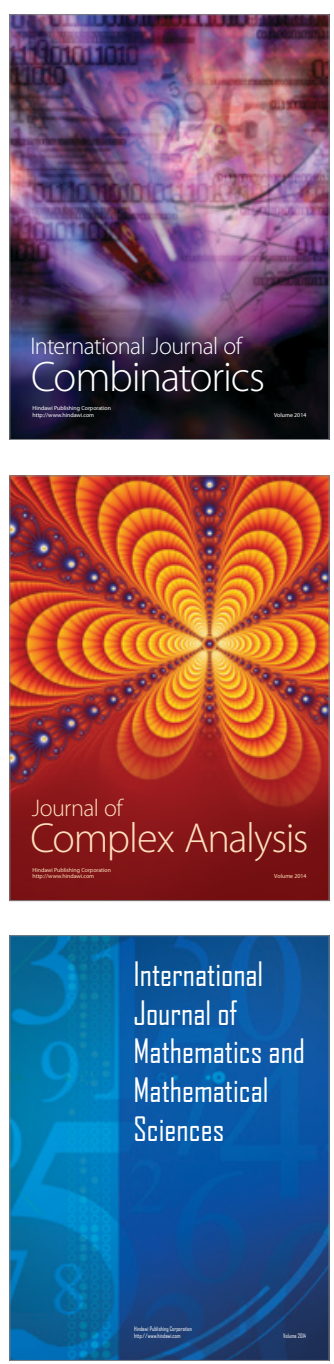
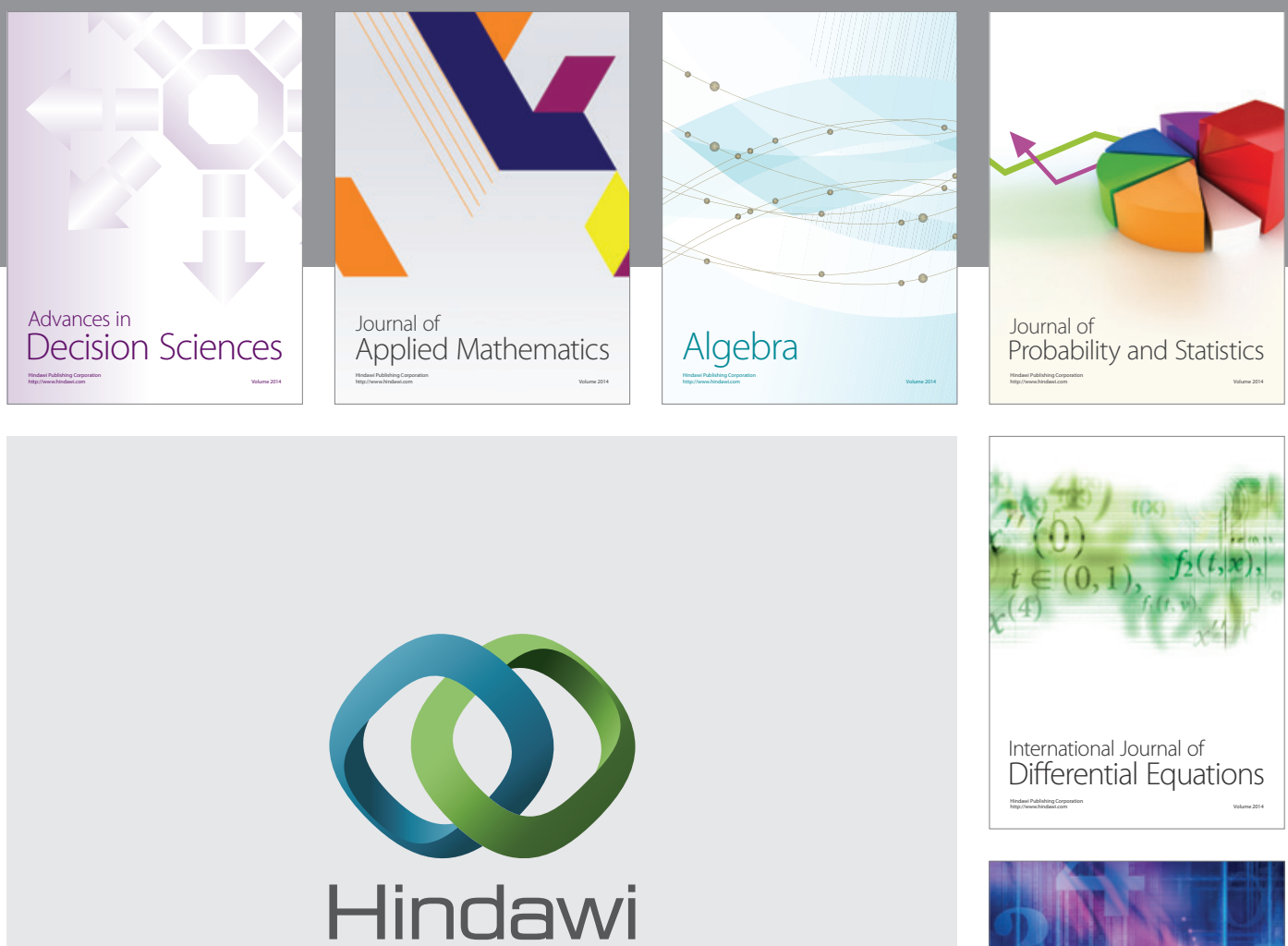

Submit your manuscripts at http://www.hindawi.com
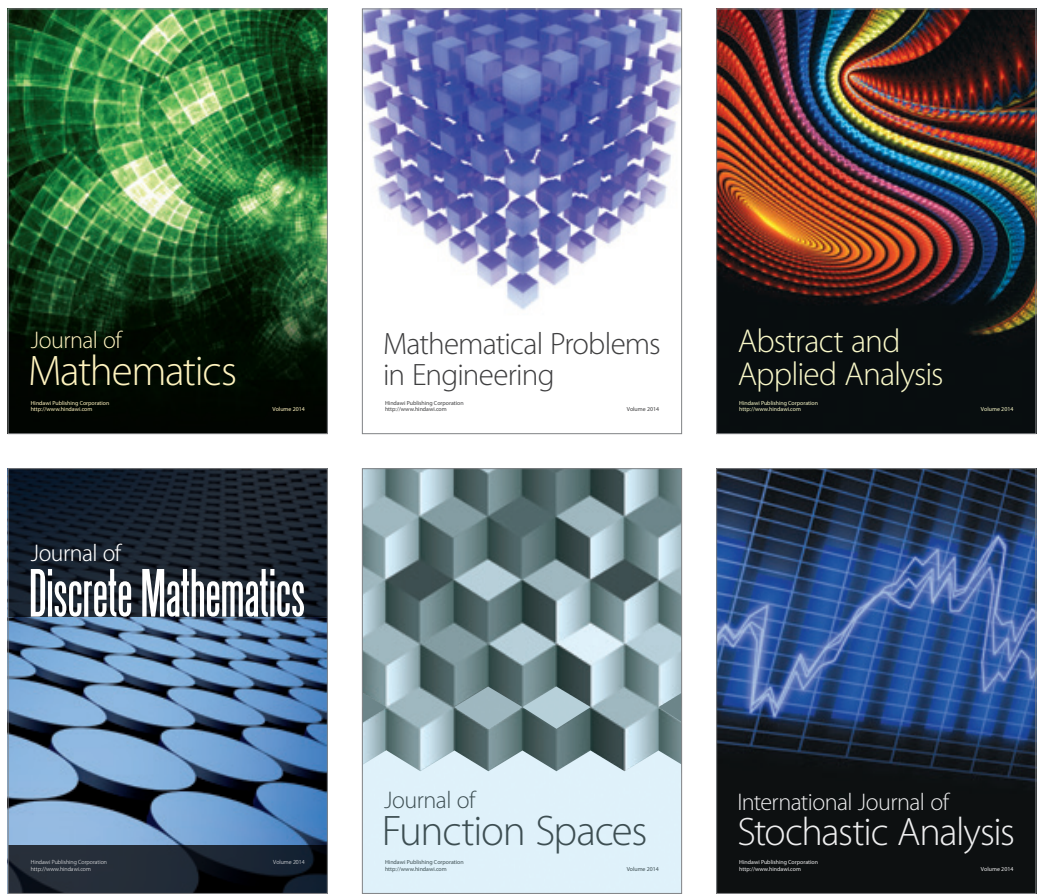

Journal of

Function Spaces

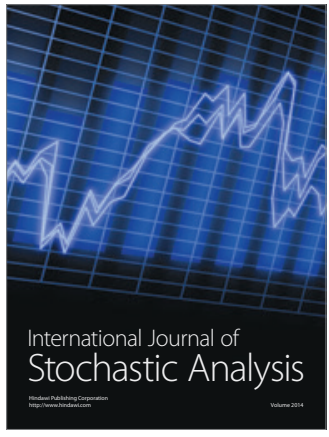

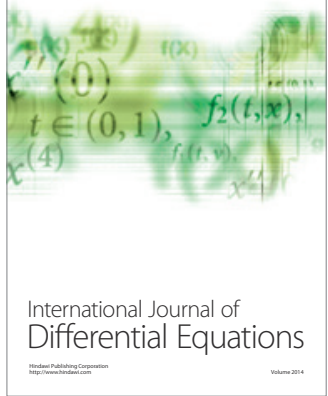
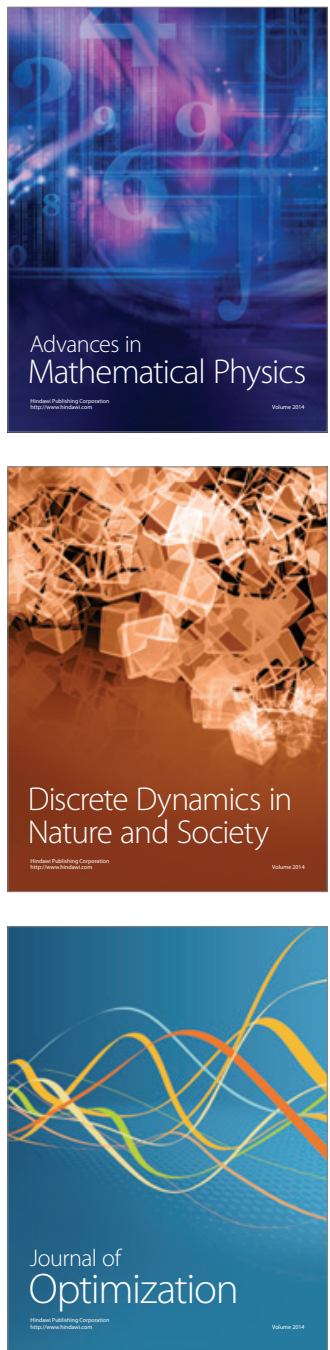